\title{
Focus as a contextual priming mechanism in reading
}

\author{
ROBIN K. MORRIS and JOCELYN R. FOLK \\ University of South Carolina, Columbia, South Carolina
}

\begin{abstract}
In two experiments, we found that readers are sensitive to manipulations of syntactically marked focus and that focus is an effective message level contextual priming mechanism. Changes in focus resulted in changes in sentence context effects on subsequent target word processing. This was demonstrated in latency to name the target word (Experiment 1) and in initial looking time on the target in silent reading (Experiment 2). Experiment 2 also revealed direct effects on the focused items, as readers made fewer regressions and spent less total time on a word that was focused than when it was not focused. However, no initial processing time effects were found on the focused word.
\end{abstract}

Word processing is a fundamental component of the reading process. Thus, our understanding of the reading process necessarily hinges in large part on our understanding of how words are processed in context. It has often been observed that words are processed more easily in related sentence contexts than in unrelated sentence contexts (Duffy, Henderson, \& Morris, 1989; Foss, 1982; Hess, Foss, \& Carroll, 1995; Morris, 1994; Simpson, Peterson, Casteel, \& Burgess, 1989; Stanovich \& West, 1979, 1981, 1983; West \& Stanovich, 1982; Whitney, McKay, Kellas, \& Emerson, 1985). However, explanations of these effects differ greatly. The purpose of the present experiments was to investigate a possible message level mechanism of sentence context effects.

Lexical level explanations of sentence context effects on word processing center on the premise that contextual facilitation arises from word-to-word priming mechanisms (intralexical priming). The assumptions underlying this position are derived from modular views of the language processing system in which the lexical processor is autonomous, acting only on information contained within the lexicon. According to this account, contextual effects are the result of activation spreading from related words in a context to the target word, speeding access of the subsequent target word (e.g., Duffy et al., 1989; Fodor, 1983; Forster, 1981; Seidenberg, Tanenhaus, Leiman, \& Bienkowski, 1982), in much the same way that semantic relatedness effects occur in word lists (e.g., Meyer \& Schvaneveldt, 1976).

While context effects on word processing in reading may arise in part from intralexical priming, there is grow-

This research was partially supported by Undergraduate Research Training Grant SBR-9400285 from the National Science Foundation. The authors thank Jennifer Mangum for her assistance in material preparation and in collecting the Experiment 1 data. J. R. Folk is now at the Department of Cognitive Science, Johns Hopkins University, Baltimore, MD. Correspondence concerning this article should be addressed to R. K. Morris, Department of Psychology, University of South Carolina, Columbia, SC 29208 (e-mail: morris@garnet.cla.sc.edu). ing consensus that this processing advantage cannot be fully accounted for by lexical level explanations. For example, there is evidence of faster processing for words in related context, even in the absence of lexical associates (e.g., Foss \& Ross, 1983; A. J. C. Sharkey \& N. E. Sharkey, 1992; N. E. Sharkey \& Mitchell, 1985), and there is a substantial body of evidence demonstrating circumstances in which lexical relatedness alone is not sufficient to produce this processing advantage (Duffy et al., 1989; Hess et al., 1995; Masson, 1986; Morris, 1994; O'Seaghdha, 1989; Potter, Moryadas, Abrams, \& Noel, 1993; Simpson et al., 1989; Williams, 1988).

Evidence that lexical relatedness alone is not sufficient to produce a word processing advantage exists in several different forms. Simpson et al. (1989) showed that sets of words that produced facilitation when embedded in a sentence context failed to produce the same effects when the same words were presented in a scrambled order. Conversely, Williams (1988) showed that a set of words that produced facilitation in the absence of a sentence frame did not yield facilitation when they were embedded in sentences. Finally, Morris (1994) demonstrated that the same set of words that produced a processing advantage for a particular target word in one sentence frame did not produce the same advantage for the same target word when the message level representation of the sentence was altered. These data pose a serious challenge to the assumptions underlying the modular view and point to the need to examine other mechanisms to account for the observed effects.

Successful sentence comprehension involves more than access of individual word meanings. Other factors, such as word order, the syntactic structure of the sentence, and the reader's knowledge, contribute to the message that the reader gleans from the reading of a sentence. According to message level accounts of contextual facilitation, emergent properties of that message level representation may influence the processing of individual words during reading. A number of emergent properties of a discourse, including causal relations and goal information 
(de Groot \& Van der Pal, 1989; Suh \& Trabasso, 1993), foregrounding (Chafe, 1972), focus (Garrod \& Sanford, 1990; Grosz, 1981; Grosz, Joshi, \& Weinstein, 1983), and discourse topic (Chafe, 1976), have been shown to influence processing. For example, it has been shown that the topic of the discourse aids in keeping related concepts active in working memory for text comprehension (Clifton \& Ferreira, 1987; Gernsbacher, Varner, \& Faust, 1990) and that items related to the topic of the discourse are more easily integrated into the discourse representation (Binder \& Morris, 1995). In addition, the items related to the topic of the discourse have been shown to be better remembered than unrelated items (Anderson, Garrod, \& Sanford, 1983; Mandler \& Goodman, 1982; O'Brien, Duffy, \& Myers, 1986). While properties of the discourse representation have been shown to influence discourse processing, the extent to which those properties influence early word processing has not been well established.

In order to investigate possible message level context effects on word processing, we used sentence focus to manipulate the message level representation of sentences. The focus manipulation allowed us to hold the lexical content of our sentences constant, while changing factors that were unique to the message of the sentence.

The focus of a sentence is the most prominent or emphasized constituent in that sentence (Halliday, 1967). The focus of the sentence may be indicated in a number of different ways. For example, focus has been implemented through the use of wh-questions (e.g., Birch \& Rayner, 1997; Blutner \& Sommer, 1988; Cutler \& Fodor, 1979), there-insertion sentences (e.g., Birch \& Garnsey, 1995), and it-cleft sentence constructions (e.g., Birch \& Garnsey, 1995; Birch \& Rayner, 1997). Focusing is thought to enhance the relative availability of concepts in memory in spoken language comprehension (Gernsbacher \& Jescheniak, 1995; Gernsbacher \& Shroyer, 1989) and in reading (Birch \& Garnsey, 1995; Birch \& Rayner, 1997; Carpenter \& Just, 1977; McKoon, Ward, Ratcliff, \& Sproat, 1993; Singer, 1976). The prominence of focused concepts in the discourse representation has also been shown to affect many different aspects of reading and listening behavior. For example, Gergely (1992) found that focusing relevant information facilitates inference drawing. McKoon, Ward, et al. (1993) found that readers resolved anaphoric referents more quickly when the antecedent was in a prominent position than when it was in a nonprominent position in the sentence. In addition, recent experiments by Tanenhaus and Spivey-Knowlton (1995) have demonstrated that focus in auditorily presented sentences can affect the accessibility of the referents of objects during inspection of a pictorial display. It has also been demonstrated that readers are more likely to detect factual errors in sentences when the errors are part of the sentence focus (Bredart \& Docquier, 1989; Bredart \& Modolo, 1988). Finally, Birch and Garnsey (1995) found facilitation for target words that were identical to previously presented focused items in a speeded recognition task with and without a delay. They interpreted this as ev- idence that focusing the word enhanced memory for that item, facilitating later recognition.

In contrast to the evidence that focus affects integration and memory processes, the literature regarding the effects of focus on lexical access of the focused item is less clear. In target detection tasks, researchers have found that listeners perceived focused information more rapidly than information that was not in focus (Cutler, 1976; Cutler \& Fodor, 1979; Hornby, 1974), and this effect was not attenuated when the intonation marking was removed and focus was operationalized solely by $w h$ - questions (Cutler \& Fodor, 1979). Blutner and Sommer (1988) also manipulated focus through the use of $w h$-questions. Their study differed from Cutler and Fodor's study in that Blutner and Sommer measured the access of the previously focused concept with a lexical decision task. They found that focused concepts were responded to faster than nonfocused concepts, supporting their claim of faster lexical retrieval for focused items. In all of these experiments, readers were cued to search for specific information (either a precued target word or the answer to a question) and to make an overt response. Under these conditions, there is consistent evidence that linguistic focus aids early word processing.

Birch and Rayner (1997) failed to find initial processing effects for focused items while monitoring readers' eye movements in a silent reading task. In one experiment, Birch and Rayner syntactically directed focus through the use of $i t$-cleft constructions; in another experiment, subjects read sentence pairs in which the first sentence was in the form of a wh-question that focused a particular entity in the second sentence. In both cases, they demonstrated differential effects of focus, but not in initial processing time measures (i.e., first fixation and gaze duration). However, these tasks differed from the previously mentioned tasks in that readers were not prompted to search for specific information. Subjects simply read the sentences as their eye movements were monitored.

All of the studies mentioned have measured what we will refer to as direct effects of focus. That is, processing time on the focused entity was the issue of interest. In the present experiments, we set out to examine focus as a mechanism of contextual facilitation for the processing of related upcoming words in the sentence. We reasoned that if discourse entities that have been focused have a more prominent position in the discourse representation, this may result in increased activation of semantically related items in the lexicon during reading. In order to test this, we returned to the materials employed by Morris (1994).

Morris (1994) demonstrated that the time to read a word varied as a function of the message level sentence context, even when the words that made up the context did not change across conditions. In those experiments, subjects read sentences, such as the following:

\footnotetext{
1 . The waiter watched as the accountant balanced the ledger the second time.

2 . The waiter who watched the accountant balanced the ledger the second time.
} 
Subjects' eye movements were monitored, and the primary dependent measure was gaze duration on the target word (ledger). Each sentence contained a verb that was semantically related to the target (balanced in this example) and two nouns, each of which was related to the verb (waiter and accountant). One of the nouns, in conjunction with the verb, was highly related to the target word (accountant + balanced). The other noun, in conjunction with the verb, was related to a very different scenario (waiter + balanced). That is, when accountants balance, the sentence is about bookkeeping, and when waiters balance, the sentence is about restaurants. Thus, the sentence message could be changed dramatically while holding the lexical content of the sentence virtually constant. Control conditions were created by replacing the critical content words with neutral words (e.g., person, woman, saw, etc.). This also provided a test of structural differences independent of the semantic constraints imposed by the content words.

Contrary to predictions of the intralexical priming account, readers spent less time on the target word (ledger) only when the accountant was balancing, and not when the sentence contained the same words, but the waiter was balancing. Thus, by altering the message of the sentence without changing the words that made up that context, sentence context effects were found on initial word processing that could not be attributed to intralexical priming. Those effects were thought to be semantic in nature, not structural, since a manipulation of the syntactic relations alone within the sentences had no effect on processing.

In the present experiments, we set out to examine more closely possible message level context effects on initial word processing. Morris (1994) found sentence context effects on initial word processing that were attributed to message level factors-specifically, to a manipulation of the topic of the sentence via agency. In the materials used in the present experiments, the $i t$-cleft construction ("It was the ...") marked the topic in a complex message that contained multiple, semantically distinct topic candidates. In Experiment 1, sentences were displayed using rapid serial visual presentation (RSVP), and naming time was the dependent measure. In Experiment 2, we monitored eye-movement patterns of silent readers. By monitoring readers' eye movements, we were able to examine processing effects on target words when prior related context words were focused, and we were able to examine direct effects of syntactic focus on the focused entity, within a single experiment.

\section{EXPERIMENT 1}

In Experiment 1, we modified the materials from Morris (1994) to emphasize either the first or the second content noun of the sentence context, using an it-cleft sentence structure to focus one of the content nouns. For example, the sentence, "The gardener watched as the barber trimmed the mustache," was modified to emphasize the gardener's presence and make the gardener the focus ("It was the gardener who watched as the barber trimmed the mustache"), or the emphasis was shifted from the gardener to the barber ("While the gardener watched, it was the barber who trimmed the mustache"). This shift in focus shifted the topic of the message from the gardener to the barber (Crystal, 1991).

We predicted that if word processing is vulnerable to message level factors, then naming time on the target words would be speeded when the focused entity was congruent with the target word, relative to when the focused entity was not congruent. That is, naming times would be faster in the congruent focus/congruent agent condition than in a structurally matched, semantically neutral content condition. Furthermore, this effect would be attenuated as focus was shifted to the incongruent noun in the incongruent focus/congruent agent condition. In addition, if the effects observed in this task were due to readers' anticipating or predicting the target word, naming time in the incongruent focus/incongruent agent condition would be slower than in the structurally matched neutral content condition. In the incongruent condition the readers' prediction would not match the presented word, and they would have to abandon their prediction to process the presented target (see Duffy et al., 1989, and Stanovich \& West, 1983, for similar arguments).

\section{Method}

Subjects. Sixty University of South Carolina undergraduates participated in this experiment for course credit. The subjects were native speakers of American English. All subjects had normal or corrected-to-normal vision.

Materials. The critical lexical content of the experimental sentence contexts consisted of two content nouns, a verb, and a target noun. There were 42 target words. Both content nouns were semantically related to the verb, but only the second noun in combination with the verb was semantically related to the target word. The first content noun was not semantically related to the target word, and, in combination with the verb, it would activate a semantic domain (i.e., a topic) that was unrelated to the target word of the sentence. We used the $i t$-cleft sentence structure ("It was the ...") to focus a particular entity and to designate the topic of the message while holding the lexical content of the sentences constant. The neutral content conditions were formed by replacing the two critical content nouns with neutral words, such as person or man. These neutral conditions acted as structurally and semantically matched control conditions for the related content conditions. Examples of each condition are presented in Table 1.

There were six content conditions formed by crossing the two variables topic (congruent focus/congruent agent, focus and agent semantically related to the target; incongruent focus/incongruent agent, focus and agent semantically unrelated to the target, incongruent focus/congruent agent, agent semantically related to the target and focus semantically unrelated) and lexical content (related or neutral). The congruent focus/congruent agent condition with its neutral content control paired with the incongruent focus/congruent agent condition with its neutral content control provided a manipulation of focus relations (focused item semantically congruent or incongruent with the target word) with agency relations held constant (always semantically congruent with the target word). The last four conditions listed in Table 1 provided a test of agency relations (congruent or incongruent with the target word) while focus relations were held constant (always incongruent with the target word).

All manipulations were made within subjects using a Latin square design so that each subject saw each of the 42 target words only 
Table 1

Example Sentence for Each Condition in Experiments 1 and 2

Content Sentence

Congruent Focus/Congruent Agent (Related Topic) Condition

1. Related While the waiter watched, it was the accountant who balanced the ledger a second time.

2. Neutral While the person watched, it was the trainee who balanced the ledger a second time.

Incongruent Focus/Incongruent Agent (Unrelated Topic) Condition

3. Related It was the waiter who watched the accountant and who balanced the ledger a second time.

4. Neutral It was the person who watched the trainee and who balanced the ledger a second time.

Incongruent Focus/Congruent Agent (Unrelated Topic) Condition

5. Related It was the waiter who watched while the accountant balanced the ledger a second time.

6. Neutral It was the person who watched while the trainee balanced the ledger a second time.

Note-The two critical content nouns are in bold, and the target word is italicized. In Experiment 1, the last word in the sentence was the target word. The line breaks in the table are not representative of the line breaks in Experiment 2. In Experiment 2, a line break occurred only after the second critical content noun.

once and only in one of the six possible context conditions. Materials were presented to each subject in a different random order. Each subject read 10 practice sentences prior to the 42 experimental sentences.

In order to ensure that no target word was predictable in the sentence contexts, 77 undergraduates participated in a two-response cloze task. They completed booklets composed of sentence fragments that contained the critical noun and verb that were semantically related to the target from each experimental sentence (e.g., "The accountant balanced the ____" The subjects were instructed to read each sentence fragment and to complete each one with the first word that came to mind and then to provide a second, alternative completion. Semantically related, yet not predictable, target words were chosen from the primary semantic domain of the cloze task completions for a given item. Words that were given as sentence completions more than $12.5 \%$ of the time were excluded from consideration as target words in the experimental sentences. The target word was always the last word in a sentence.

Procedure. To begin a trial, a plus sign was presented at the center of the computer screen for $1,000 \mathrm{msec}$ as a fixation marker for the subject. The first word in a sentence replaced the plus sign, followed by the rest of the words in a sentence, one at a time every $250 \mathrm{msec}$. The next to last word appeared on the computer screen with a plus sign above and below it. The plus signs signaled the subject to name the next word out loud. The target word appeared next and remained on the screen until the subject made a response.

The experimenter instructed each subject to read the sentences silently to himself or herself and to name the last word in a sentence out loud as quickly and as accurately as possible. After each trial, the question "OK?" appeared on the screen. The experimenter instructed each subject to press the "yes" button if he or she had responded correctly on that trial. If the subject made an error by stumbling on the target word or by saying the wrong word, he or she was instructed to press the "no" button. After the subject pressed a button to answer the question, the fixation plus sign for the next trial appeared on the screen. The experimenter was in the room during testing and also coded errors. Each subject was tested individually and received 10 practice trials before the experimental trials. The experimenter asked "yes"/"no" comprehension questions on ap proximately one third of the trials. A session lasted approximately $15 \mathrm{~min}$.
Apparatus. The stimuli were presented on an IBM PS/2 8512 color display monitor that was controlled by an IBM PS/2 Model 70 386 computer. A microphone connected to a voice-activated relay and interfaced with a digital $\mathrm{I} / \mathrm{O}$ port on the computer was used to collect the naming latencies.

\section{Results}

Any naming response that was 2.5 standard deviations from a subject's overall mean was dropped from the analyses in order to eliminate outliers from the data. This resulted in a loss of $2 \%$ of the data. Another $5 \%$ of the data was lost when naming and comprehension errors were removed from the analyses. The error trials were evenly distributed across experimental conditions. All of the analyses were performed using both subject $(F 1)$ and item $(F 2)$ variability, and both sets of means are presented in the tables.

The data from Experiment 1 are presented in Table 2. We predicted that when the focus of the sentence established a topic that was semantically related to the target word, this would lead to faster naming of the target word, but not when the focus established a semantically unrelated topic. The relevant pairwise comparisons support this interpretation. That is, there was a naming-time advantage for the congruent focus/congruent agent condition, relative to its matched neutral content condition. This effect was reliable by subjects but not by items $\left[F 1(1,59)=5.50, M S_{\mathrm{c}}=964, p<.05 ; F 2(1,41)=1.84\right.$, $\left.M S_{\mathrm{e}}=1,511, p>.15\right]$. When the topic of the sentence was shifted to an incongruent semantic domain in the incongruent focus/congruent agent condition, no facilitation was found on the target word, relative to the matched neutral content condition $(F \mathrm{~s}<1)$. However, owing to the small effect size, the interaction was not reliable $[F 1(1,59)$ $\left.=1.53, M S_{\mathrm{e}}=612, p=.22 ; F 2<1\right]$.

There was no evidence of a processing advantage on the target word due to agency alone when the focus established a semantically unrelated topic. That is, there was not a reliable interaction when the difference between the incongruent focus/incongruent agent condition and its neutral content condition was compared with the difference between the incongruent focus/congruent

Table 2

Mean Naming Latencies and Gaze Durations (in Milliseconds) for the Target Word in Experiments 1 and 2

\begin{tabular}{|c|c|c|c|c|}
\hline \multirow[b]{2}{*}{ Content } & \multicolumn{2}{|c|}{$\begin{array}{l}\text { Naming } \\
\text { Latency }\end{array}$} & \multicolumn{2}{|c|}{$\begin{array}{c}\text { Gaze } \\
\text { Duration } \\
\end{array}$} \\
\hline & Subjects & (Items) & Subjects & (Items) \\
\hline
\end{tabular}

Congruent Focus/Congruent Agent (Related Topic) Condition

Related $\quad 599 \quad$ (602) $\quad 316$

Neutral $613 \quad(614) \quad 343 \quad$ (344)

Incongruent Focus/Incongruent Agent (Unrelated Topic) Condition

$\begin{array}{lllll}\text { Related } & 612 & (611) & 337\end{array}$

Neutral $614 \quad$ (617) 341

Incongruent Focus/Congruent Agent (Unrelated Topic) Condition

\begin{tabular}{lllll} 
Related & 611 & $(613)$ & 346 & $(345)$ \\
Neutral & 616 & $(620)$ & 332 & $(332)$ \\
\hline
\end{tabular}


agent condition and its neutral content condition $(F \mathbf{s}<1)$. There was no evidence that these results were influenced by the subjects' anticipating a particular word, since the incongruent focus/incongruent agent condition was not slower than its control condition $(F \mathbf{s}<1)$.

\section{Discussion}

In Experiment 1, we demonstrated message level context effects that were attributable to a local manipulation of topic within a sentence. We compared the time to recognize a target word in a sentence context when focus was used to establish a topic that was semantically related to the target with a case in which the context contained the same words, but the focus established a topic that was semantically unrelated to the target. We found a processing advantage for the target only in the focused case. No facilitation was found when the focus shifted the topic to a semantic domain that was unrelated to the target word (in the incongruent focus/congruent agent condition or in the incongruent focus/incongruent agent condition). These results are consistent with Morris's (1994) conclusion that context effects emanating from the message level representation of a sentence context are possible.

\section{EXPERIMENT 2}

The results of Experiment 1 were suggestive, but not robust. This led us to question whether the small effects from the naming-time procedure would replicate in an on-line silent reading task. We addressed this question by using the materials from Experiment 1, but changing the methodology so that the subjects' eye movements were monitored as they read silently for comprehension. This methodology allowed us to assess focus as a contextual priming mechanism by examining gaze durations on the target word. We also added 42 filler sentences to the material set to dilute any strategic effects due to the repeated sentence structure.

We were also able to assess the effects of the $i t$-cleft construction on the focused items. By examining gaze durations on the critical content words in the sentence context (e.g., accountant or waiter) as a function of focus, we were able to evaluate initial processing effects of focus. The existing literature is inconsistent on this point, with some studies showing an encoding advantage for focused items (Blutner \& Sommer, 1988; Cutler, 1976; Cutler \& Fodor, 1979; Hornby, 1974) and some not (Birch \& Rayner, 1997). We were also able to assess text integration and reanalysis of the focused items by examining regressions to the focused items and total time spent on those items. The earlier literature suggests that focused items may occupy a more prominent position in the text representation, thereby making them easier to integrate with later information (Gergely, 1992; Gernsbacher \& Jescheniak, 1995; Gernsbacher \& Shroyer, 1989; McKoon, Ratcliff, Ward, \& Sproat, 1993). This might be expressed in the eye-movement record in fewer regressions to the focused item, or less reanalysis time on the word, or both.

\section{Method}

Subjects. Thirty-six University of South Carolina undergraduates participated in this experiment for course credit. The subjects were native speakers of American English. All subjects had normal uncorrected vision, and none had participated in Experiment 1.

Materials. The materials from Experiment 1 were used after minor modifications were made to them. A short phrase was added to the end of each sentence so that the target word would not be the last word in a sentence. In addition, we modified some sentences to make the syntactic structure of the sentences in each condition more uniform and added 42 filler sentences that differed in sentence structure from the experimental items. The design was the same as in Experiment 1.

Procedure. At the beginning of a session, the experimenter prepared a bite bar for the subject. The bite bar was used to eliminate head movements by the subject during testing. The experimenter encouraged each subject to read normally for comprehension and informed the subjects that "yes/no" comprehension questions would be asked following their reading of some sentences. The eye-tracking system was aligned and calibrated for each subject, which took approximately $5 \mathrm{~min}$.

To begin a trial, a row of five target boxes was displayed on the computer screen. The left target box marked the position where the first letter of a sentence would appear. The subject was told to look at the left box when he or she was ready for a trial to begin, and the experimenter would then present a sentence. The subject pushed a button to remove the sentence from the screen when he or she was finished reading, and the sentence was replaced by the row of target boxes. The experimenter asked a comprehension question after every 6 th sentence on average, and all subjects performed at $90 \%$ accuracy or better on the comprehension questions.

Each subject was tested individually and read four practice trials to become familiar with the testing procedure prior to reading the experimental sentences. A session lasted approximately $30 \mathrm{~min}$.

Apparatus. A Fourward Technologies Dual Purkinje Image eyemovement monitoring system was used to record the subjects' eye movements. Eye movements were recorded from the right eye, and viewing was binocular. An IBM PS/2 model 80 computer controlled the stimulus display and data storage and was interfaced with the eye tracker. Each sentence was double spaced and presented on two lines. All of the characters were presented in lowercase, except for the first word of each sentence. There were up to 71 characters per line, and 4 character spaces equaled $1^{\circ}$ of visual angle. The eye tracker sampled a subject's eye position every millisecond, with a resolution of $10^{\prime}$ of arc. The sentences were displayed on an IBM $\mathrm{PS} / 28512$ color monitor

\section{Results}

Target noun data. Table 2 contains the gaze duration means on the target noun. As in Experiment 1, we predicted a processing advantage when the focus of the sentence established a topic that was semantically related to the target word, but not when the focus established a semantically unrelated topic. This was demonstrated by a reliable interaction in the $2 \times 2$ analysis of variance (ANOVA) comparing the congruent focus/congruent agent condition and its neutral content condition with the incongruent focus/congruent agent condition and its neutral content condition $\left[F 1(1,35)=5.03, M S_{\mathrm{e}}=\right.$ $\left.2,570, p<.05 ; F 2(1,41)=3.54, M S_{\mathrm{e}}=5,154, p<.07\right]$. Furthermore, the predicted details of that interaction were supported by the relevant pairwise comparisons. That is, gaze duration on the target word was shorter in the congruent focus/congruent agent condition than in its neu- 
tral content condition $\left[F 1(1,35)=5.03, M S_{\mathrm{e}}=2,570\right.$ $\left.p<.05 ; F 2(1,41)=4.50, M S_{\mathrm{e}}=4,006, p<.05\right]$. There was no reliable difference in gaze duration on the target word in the incongruent focus/congruent agent condition relative to its neutral content condition $[F 1(1,35)=1.39$, $\left.M S_{\mathrm{e}}=2,694, p>.24 ; F 2<1\right]$. These effects are consistent with, but more robust than, the results obtained in the RSVP naming task.

Again, agency alone had no effect when the focus established a semantically unrelated topic, as measured by the interaction of the incongruent focus/incongruent agent condition and its neutral content condition with the incongruent focus/congruent agent condition and its neutral content condition $(F \mathrm{~s}<1)$. There were no reliable effects in the reanalysis measures (total time, regressions to the target word, or regressions away from the target).

Direct effects of focus. We examined processing time on the first and second content noun to evaluate differential processing of the specific focused item. This allowed for the assessment of the direct effect of this structural marking on initial encoding and text integration during reading. These two regions (first noun, second noun) were analyzed separately in order to avoid potential confounding effects due to differences in ordinal and structural sentence position. We concentrated our analyses on the congruent focus/congruent agent condition and the incongruent focus/congruent agent condition, unless otherwise indicated, since these two conditions varied which item was in focus while lexical content and agent relations remained constant. This also allowed us to compare processing time on the same word in differing context conditions. The first-noun-focused data came from the incongruent focus/congruent agent condition, and the first-noun-not-focused data came from the congruent focus/congruent agent condition. In the case of the second noun, the conditions were reversed. The second noun was focused in the congruent focus/ congruent agent condition, and not in the incongruent focus/congruent agent condition. The structurally matched neutral content conditions were analyzed separately, since the neutral replacement words in the control conditions were not matched for frequency to the semantic content words.

Direct effects on initial encoding. As the gaze duration means in Table 3 suggest, there were no observed processing differences for focused items at encoding in either the first-noun data $\left[F 1(1,35)=1.11, M S_{\mathrm{e}}=4,304\right.$, $\left.p>.29 ; F 2(1,41)=1.72, M S_{\mathrm{e}}=2,876, p>.19\right]$ or the second-noun data $\left[F 1<1 ; F 2(1,41)=1.17, M S_{\mathrm{e}}=\right.$ $4,597, p>.28]$.

Direct effects on text integration. Text integration effects were assessed by looking at total time on the critical word, the percentage of trials on which the subjects made regressions to the critical word (regressions in), and the percentage of trials on which the subjects made regressions to other regions of the sentence upon encountering the critical word (regressions out). These data are presented in Table 3.

The advantage of focused items over not focused items in measures of text integration was striking. The subjects spent less total time on focused items than on items that were not focused, as shown in the total time spent on the focused second noun relative to that spent on the notfocused second noun $\left[F 1(1,35)=6.23, M S_{\mathrm{e}}=5,844\right.$, $\left.p<.05 ; F 2(1,41)=9.83, M S_{\mathrm{e}}=9,517, p<.01\right]$. The pattern was the same in the first-noun data, but the effect was marginal in the subject data $[F 1(1,35)=2.97$, $\left.M S_{\mathrm{e}}=9,062, p<.09\right]$ and not reliable by items $(F 2<1)$. This processing advantage for focused items was also expressed in the decreased frequency with which the subjects regressed to the first noun when it was focused relative to when it was not $\left[F 1(1,35)=11.62, M S_{\mathrm{e}}=329\right.$, $\left.p<.01 ; F 2(1,41)=10.05, M S_{\mathrm{e}}=389, p<.01\right]$. That is, the subjects made fewer regressions to a focused item than to a nonfocused item. In addition, focused items tended to prompt fewer regressions to other regions of the sentence than did nonfocused items. This trend was consistent, but not of a reliable magnitude in either the Noun 1 or the Noun 2 data.

The focus effects were present regardless of the semantic relationship between the content noun and the target word. That is, Noun 1 was always semantically unrelated to target word, and Noun 2 was always semantically related; however, there was an effect of focus in both cases. The focus effect interpretation is further supported by the fact that similar effects were obtained in the neutral content conditions in which Noun 1 and Noun 2 were neutral with respect to their semantic relation to the target. The means for these conditions are shown in Table 4. Again, the subjects spent less total time on the second noun when it was focused than when it was not $\left[F 1(1,35)=4.97, M S_{\mathrm{e}}=8,223, p<.05\right.$; $\left.F 2(1,41)=3.76, M S_{\mathrm{e}}=7,033, p=.06\right]$. The pattern was similar for the first-noun data, but the effect was not

Table 3

Direct Effects of Focus on the Related Content Nouns in Experiment 2

\begin{tabular}{|c|c|c|c|c|c|c|c|c|c|c|c|c|c|c|c|}
\hline \multirow[b]{3}{*}{ Condition } & \multicolumn{4}{|c|}{ Gaze Duration (msec) } & \multicolumn{4}{|c|}{ Total Time (msec) } & \multicolumn{4}{|c|}{ Regressions In $(\%)$} & \multicolumn{3}{|c|}{ Regressions Out (\%) } \\
\hline & \multicolumn{2}{|c|}{ Noun 1} & \multicolumn{2}{|c|}{ Noun 2} & \multicolumn{2}{|c|}{ Noun 1} & \multicolumn{2}{|c|}{ Noun 2} & \multicolumn{2}{|c|}{ Noun 1} & \multicolumn{2}{|c|}{ Noun 2} & \multicolumn{2}{|c|}{ Noun 1} & \multirow{2}{*}{$\frac{\text { Noun } 2}{\text { Subject (Item) }}$} \\
\hline & Subject & (Item) & Subject & (Item) & Subject & (Item) & Subject & (Item) & Subject & (Item) & Subject & $($ (Item) & Subject & $\overline{(\text { Item) }}$ & \\
\hline & & (2) & & & & & & & & & & & 4 & & 16 \\
\hline Not focus & 289 & $(290)$ & 308 & (308) & 491 & $(472)$ & 407 & (411) & 32 & (32) & 17 & (18) & 18 & (18) & (23) \\
\hline
\end{tabular}

Note - Columns give subject means and item means. Noun 1/Focus data and Noun $2 /$ Not focus data come from the Incongruent focus/congruent agent condition (Condition 5 in Table 1). Noun 1/Not focus data and Noun $2 /$ Focus data come from the congruent focus/congruent agent condition (Condition 1 in Table 1 ). 
Table 4

Direct Effects of Focus on the Neutral Content Nouns

\begin{tabular}{|c|c|c|c|c|c|c|c|c|}
\hline \multirow[b]{3}{*}{ Condition } & \multicolumn{4}{|c|}{ Total Time (msec) } & \multicolumn{4}{|c|}{ Regressions In (\%) } \\
\hline & \multicolumn{2}{|c|}{ Noun 1} & \multicolumn{2}{|c|}{ Noun 2} & \multicolumn{2}{|c|}{ Noun 1} & \multicolumn{2}{|c|}{ Noun 2} \\
\hline & Subject & $($ Item) & Subjec & (Item) & Subjec & (Item) & Subjec & (Item) \\
\hline Focus & 406 & $(414)$ & 309 & (311) & 21 & (19) & 26 & (25) \\
\hline Not focus & 441 & $(439)$ & 357 & $(346)$ & 30 & $(30)$ & 25 & $(24)$ \\
\hline
\end{tabular}

reliable $\left[F 1(1,35)=2.28, M S_{\mathrm{e}}=11,495, p=.14 ; F 2<\right.$ 1]. The subjects also regressed less often to the first noun when it was focused than when it was not $[F 1(1,35)=$ $3.64, M S_{\mathrm{e}}=423, p=.06 ; F 2(1,41)=6.98, M S_{\mathrm{e}}=315$, $p<.05]$. Finally, we went back to the data from Morris's (1994) Experiment 2 and analyzed total time and regressions to the first and second content noun in the "related message-new noun added" and the "altered messagenew noun added" conditions. These conditions differed from the content Noun 1 and content Noun 2 conditions of the present experiment only in that they did not include the $i t$-cleft focus manipulation. However, as is apparent in the example sentences provided in the introduction to this paper, semantic relations were the same in both experiments. These analyses yielded no significant effects. Thus, it is unlikely that the text integration advantage for focused items over nonfocused items was due to the semantic relations between the focused entity and the target word, since this processing advantage extended to the neutral content noun conditions and not to conditions in which there was no focus manipulation.

There were also differences between Noun 1 and Noun 2 processing, regardless of focus. The subjects regressed less frequently ( $17.5 \%$ vs. $24.5 \%)$ overall and spent less total time ( 385 vs. $472 \mathrm{msec}$ ) overall on the second content noun in the related condition than on the first content noun, respectively. There are several ways in which Noun 1 and Noun 2 differed from one another in this experiment. The second noun was always semantically consistent with the remainder of the sentence, and the first noun was not. However, there were similar differences in overall processing time between neutral Noun 1 and neutral Noun 2 (see Table 4), so it is unlikely that semantic relations can account for the difference.

It is also the case that, in both conditions that were tested, the second noun served as the agent of the main action of the sentence, and the first noun did not. Therefore, the Noun 1-Noun 2 difference may reflect an effect of agency. We examined this further by comparing total time on the first noun ( $459 \mathrm{vs.} 452 \mathrm{msec}$ ) and regressions to the first noun ( $20 \%$ vs. $17 \%$ ) in the incongruent focus/ incongruent agent condition and the incongruent focus/ congruent agent condition, respectively. Semantic relatedness and focus were constant, and agency varied across these two conditions. In the incongruent focus/incongruent agent condition, the first noun was the agent; in the incongruent focus/congruent agent condition, it was not. If the observed differences between the first- and secondnoun data reported in Table 3 were due to differences in agent relations, then there should have been differences in processing time on Noun 1 in these two conditions. This was clearly not the case (all $F_{\mathrm{s}}<1$, by subjects and items). Given that there were no differences in processing time on Noun 1 when agency relations were manipulated, this argues against the agency explanation. However, if readers have greatest access to information in the most recent clause, as Gernsbacher, Hargreaves, and Beeman (1989) suggest, this could explain the Noun 2 processing advantage. Noun 2 always appeared in the most recent clause, and there was a consistent processing advantage for the second noun relative to the first noun, regardless of semantic relations, focus, or agency.

\section{Discussion}

There were three important findings in Experiment 2. First, we found evidence of message level context influencing initial word processing. The subjects spent less initial processing time on the target words when semantically related context words were highlighted through the use of linguistic focus than when semantically unrelated words were in focus. This is consistent with the findings obtained in Experiment 1 and suggests that focus, as a manipulation of topic, is an effective contextual mechanism in word processing during reading. Second, there was no evidence that words were accessed more rapidly when they were in focus than when they were not; we found no evidence that focus has a direct effect on initial word processing. This is consistent with Birch and Rayner (1997). Finally, the subjects were less likely to regress to and spent less total reading on focused entities than on the same entities when they were not focused. This indicates that focusing eased text integration, which is consistent with the prior literature that indicates that focus influences memory for, and comprehension of, text.

\section{GENERAL DISCUSSION}

The results of these experiments demonstrate that readers are sensitive to manipulations of sentence focus, as reflected in the subjects' naming latencies and eyemovement patterns. We were able to examine focus as a possible message level contextual priming mechanism in two ways: (1) by manipulating focus in context to examine processing effects on a subsequent target word, and (2) by examining processing effects on the focused item itself.

Our results are inconsistent with lexical level explanations of sentence context effects, including combinatory intralexical priming accounts such as that proposed by Duffy et al. (1989). According to the combinatory account, activation from multiple lexical items may converge to prime a target word in the absence of priming from any single lexical item. However, this type of model cannot 
account for changes in the pattern of facilitation when the lexical content of the sentence remains constant, as was the case in these experiments (see also Morris, 1994).

An alternative lexical priming account in which focus increases the activation of the focused item's lexical entry, thereby rendering it a stronger prime of related items within the lexicon, is also unlikely. According to such an account when the semantically related content noun is focused, processing on the target word should be facilitated; likewise, when focus shifts to the semantically unrelated content word, the facilitation should be attenuated. While this basic pattern was obtained in the target word data, there are several other aspects of the data that are inconsistent with this account. First, the semantic relationship between the focused item and the target word was not strong. The materials used in the present experiments were designed so that each individual context word was only moderately related to the target word. Subjects in a norming task produced the target words as one of their first two responses to the content noun and verb pairs less than $13 \%$ of the time. While focus might increase the activation strength of the focused item, it is not clear how it could change the strength of the intralexical associative link between the focused item and the target word. In addition, there were a number of words intervening between the content noun and target word. The initial processing time data for the focused items are also not consistent with an intralexical priming account. If focus increases the activation of the focused word in the lexicon, then we would expect to see differential initial processing time effects on those words. However, when we looked at processing time directly on the focused items in Experiment 2, we observed no initial processing time differences on focused versus unfocused items as measured by gaze durations. Birch and Rayner (1997) also failed to find initial processing effects on focused items in reading.

It may still be possible to construct an intralexical priming account of the results obtained in the present experiments if we assume that focus provides a mechanism by which a lexical item can accumulate more activation per unit of time during its initial encoding and thus act as a stronger prime for related lexical items. There are at least two problems with this position. First, according to this account, increased activation of the lexical entry is not reflected in decreased processing time on that word. Yet, we would want to argue that the decreased processing time on the subsequent target word reflects greater activation from the focused item to that lexical entry. Second, according to this account, we must assume that greater activation of one lexical entry results in wider dispersion of activation from that entry to other entries in the lexicon than would otherwise occur. That is, the activated item will now prime other items that it would not otherwise prime. Finally, even if we modify the intralexical priming account to accommodate these data, it still will not account for previously reported sentence context effects on lexical access (e.g., Morris, 1994; A. J. C. Sharkey \& N. E. Sharkey, 1992; Simpson et al., 1989).
The dissociation between initial processing time on the focused item and later processing time on the same item was quite distinctive. The absence of any initial processing advantage for the focused entity, paired with the fact that there was a reliable processing advantage in the text integration measures, suggests that the focus advantage arises from the differential status of the focused entity in the discourse representation, rather than from increased activation at the lexical level. Text-based priming mechanisms that rely on intralexical relations as their base (e.g., Kintsch, 1988) would not predict these results, given that the lexical associative relations between the focused item and the target are weak. A connectionist model of text-based priming that incorporates contextual constraint from sources beyond a lexical level, such as Sharkey and Sharkey's lexical distance model could account for these, and other, sentence level context effects on initial stages of lexical processing in the absence of intralexical priming. However, it is important to note that this mechanism as currently developed might also allow for effects of syntactic constraint, which we did not observe in these data.

Although the $i t$-cleft construction is a syntactic marking device, structural differences alone cannot account for our results. In our experiments, each context condition was paired with a structurally matched semantically neutral control. If structural differences account for the observed effects, then we would expect to see parallel effects in the content conditions and their structurally matched controls, and this did not occur. We have demonstrated effects of the semantic aspects of the message, but we have no data to support any influence of syntactic structure per se influencing this process. Duffy et al. (1989) and Morris (1994), using similar materials, also found no effect of manipulating syntactic relations alone. In addition, Rayner, Garrod, and Perfetti (1992) and Britt, Perfetti, Garrod, and Rayner (1992) have demonstrated that, while recovery from parsing difficulty is aided by discourse focus, initial sentence parsing is impervious to this information. O'Seaghdha (1989) has also dissociated the effects of syntactic processing from semantic effects at the message level and has argued that syntactic and meaning level processes are fundamentally distinct. We believe that the syntactic analysis influenced sentence context effects in our experiments only to the extent that it influenced the configuration and therefore the content of the sentence message (see also Birch \& Garnsey, 1995; Kintsch, 1992; McKoon, Ratcliff, et al., 1993).

In our study, we implemented the it-cleft construction in a complex sentence that contained multiple semantically distinct topic candidates. This focus device distinctly marked the topic of the sentence. Our initial processing time data for the focused noun (i.e., the topic of the sentence) suggest that the $i t$-cleft construction does not influence the initial encoding of the focused word. However, later processing measures support the notion that the focused item is more easily integrated to form a more coherent text representation (McKoon, Ward, et al., 1993) and has a more prominent position in that repre- 
sentation (Gergely, 1992; Gernsbacher \& Jescheniak, 1995; Gernsbacher \& Shroyer, 1989; McKoon, Ratcliff, et al., 1993). This in turn results in increased activation of semantically related items in the lexicon, as demonstrated by naming latency and gaze duration effects on the target word. Thus, the observed context effects on the target words in our study emanated from properties unique to the message level representation.

\section{REFERENCES}

Anderson, A., Garrod, S., \& Sanford, A. J. (1983). The accessibility of pronomial antecedents as a function of episode shifts in narrative text. Quarterly Journal of Experimental Psychology, 35A, 427-440.

Binder, K. S., \& MORRIS, R. K. (1995). Eye movements and lexical ambiguity resolution: Effects of prior encounter and discourse topic Journal of Experimental Psychology: Learning, Memory, \& Cognition, 21, 1186-1196.

BiRCH, S. L., \& GaRnSEY, S. M. (1995). The effect of focus on memory for words in sentences. Journal of Memory \& Language, 34, 232-267.

BIRCH, S. [L.], \& RAYNER, K. (1997). Linguistic focus affects eye movements during reading. Memory \& Cognition, 25, 653-660.

Blutner, R., \& SOMmer, R. (1988). Sentence processing and lexical access: The influence of the focus-identifying task. Journal of Memory \& Language, $27,359-367$

BredarT, S., \& Docquier, M. (1989). The Moses illusion: A follow-up on the focalization effect. Cahiers de Psychologie Cognitive, 9 , 357-362.

BredarT, S., \& Modolo, K. (1988). Moses strikes again: Focalization effect on a semantic illusion. Acta Psychologica, 67, 135-144.

Britt, M. A., Perfetti, C. A., Garrod, S., \& Rayner, K. (1992). Parsing in discourse: Context effects and their limits. Journal of Memory \& Language, 31, 293-314.

CARPENTER, P. A., \& Just, M. A. (1977). Integrative processes in comprehension. In P. LaBerge \& S. J. Samuels (Eds.), Basic processes in reading: Perception and comprehension (pp. 217-241). Hillsdale, $\mathrm{NJ}$ : Erlbaum.

Chafe, W. L. (1972). Discourse structure and human knowledge. In J. B. Carroll \& R. O. Freedle (Eds.), Language comprehension and the acquisition of knowledge (pp. 111-133). Washington, DC: Winston.

ChafE, W. [L.] (1976). Givenness, contrastiveness, definiteness, subjects, and topics. In C. N. Li (Ed.), Subject and topic (pp. 25-55). New York: Academic Press.

Clifton, C., Jr., \& Ferreira, F. (1987). Discourse structure and anaphora: Some experimental results. In M. Coltheart (Ed.), Attention and performance $X I I$ (pp. 635-654). Hillsdale, NJ: Erlbaum.

CRYSTAL, D. (1991). A dictionary of linguistics and phonetics (3rd ed.). Cambridge, MA: Blackwell.

CUTLER, A. (1976). Phoneme-monitoring reaction time as a function of preceding intonation contour. Perception \& Psychophysics, 20, 55-60.

Cutler, A., \& Fodor, J. A. (1979). Semantic focus and sentence comprehension. Cognition, 7, 49-59.

DE GRoOT, A. M., \& VAN DER PAL, F. (1989). Causal linking during text comprehension. Psychological Reports, 65, 379-384.

Duffy, S. A., Henderson, J. M., \& Morris, R. K. (1989). The semantic facilitation of lexical access during sentence processing. Journal of Experimental Psychology: Learning, Memory, \& Cognition, 15, 791-801.

Fodor, J. A. (1983). Modularity of mind. Cambridge, MA: MIT Press.

Forster, K. I. (1981). Priming and the effects on sentence and lexical contexts on naming time: Evidence for autonomous lexical processing. Quarterly Journal of Experimental Psychology, 33A, 465-495.

Foss, D. J. (1982). A discourse on semantic priming. Cognitive Psychology, 14, 590-607.

Foss, D. J., \& Ross, J. R. (1983). Great expectations: Context effects during sentence processing. In G. B. Flores d'Arcais \& R. J. Jarvella (Eds.), The process of language understanding (pp. 169-191). Chichester, U.K.: Wiley.
GaRrod, S., \& SANFORD, A. J. (1990). Referential processing in reading: Focusing on roles and individuals. In D. A. Balota, G. B. Flores d'Arcais, \& K. Rayner (Eds.), Comprehension processes in reading (pp. 465-485). Hillsdale, NJ: Erlbaum.

GERGELY, G. (1992). Focus-based inferences in sentence comprehension. In I. A. Sag \& A. Szabolesi (Eds.), Lexical matters (pp. 47-65). Stanford, CA: Stanford Center for the Study of Language and Information.

Gernsbacher, M. A., Hargreaves, D. J., \& Beeman, M. (1989). Building and accessing clausal representations: The advantage of first mention versus the advantage of clause recency. Journal of Memory \& Language, 28, 735-755.

GernsBacher, M. A., \& JescheniaK, J. (1995). Cataphoric devices in spoken discourse. Cognitive Psychology, 29, 24-58.

Gernsbacher, M. A., \& Shroyer, S. (1989). The cataphoric use of the indefinite this in spoken narratives. Memory \& Cognition, 17, 536-540.

Gernsbacher, M. A., VARner, K. R., \& Faust, M. E. (1990). Investigating differences in general comprehension skill. Journal of Experimental Psychology: Learning, Memory, \& Cognition, 16, 430-445.

Grosz, B. (1981). Focusing and description in natural language dialogues. In A. Joshi, B. Webber, \& I. Sag (Eds.), Elements of discourse understanding (pp. 84-105). Cambridge: Cambridge University Press.

Grosz, B., JoshI, A., \& Weinstein, S. (1983). Providing a unified account of definite noun phrases in discourse. In Proceedings of the Ninth International Joint Conference on Artificial Intelligence (pp. 44-50). Cambridge, MA: AIC.

HaLLIDAY, M. A. K. (1967). Notes on transitivity and theme in English, part 2. Journal of Linguistics, 3, 199-244.

Hess, D. J., Foss, D. J., \& Carroll, P. (1995). Effects of global and local context on lexical processing during language. Journal of Experimental Psychology: General, 124, 62-82.

HORNBY, P. A. (1974). Surface structure and presupposition. Journal of Verbal Learning \& Verbal Behavior, 13, 530-538.

KINTSCH, W. (1988). The role of knowledge in discourse comprehension: A construction-integration model. Psychological Review, 95, 163-182.

KINTSCH, W. (1992). How readers construct situation models for stories: The role of syntactic cues and causal inferences. In A. F. Healy, S. M. Kosslyn, \& R. M. Shiffrin (Eds.), From learning processes to cognitive processes: Essays in honor of William K. Estes (pp. 261278). Hillsdale, NJ: Erlbaum.

MANDLER, J. M., \& Goodman, M. S. (1982). On the psychological validity of story structure. Journal of Verbal Learning \& Verbal Behavior, 21, 507-523

MASSON, M. E. J. (1986). Comprehension of rapidly presented sentences: The mind is quicker than the eye. Journal of Memory \& Language, 25, 588-604.

McKoon, G., Ratcliff, R., Ward, G., \& Sproat, R. (1993). Syntactic prominence effects on discourse processes. Journal of Memory \& Language, 32, 593-607.

McKoon, G., Ward, G., RatclifF, R., \& Sproat, R. (1993). Morphosyntactic and pragmatic factors affecting the accessibility of discourse entities. Journal of Memory \& Language, 32, 56-75.

MeYer, D. E., \& SCh VANEVELdT, R. W. (1976). Meaning, memory structure, and mental processes. Science, 197, 27-33.

MoRRIS, R. K. (1994). Lexical and message-level sentence context effects on fixation times in reading. Journal of Experimental Psychology: Learning, Memory, \& Cognition, 20, 92-103.

O'BRIEN, E. J., DUFFY, S. A., \& MyERs, J. A. (1986). Anaphoric inferences in reading. Journal of Experimental Psychology: Learning, Memory, \& Cognition, 12, 346-352.

O'SEAGHDHA, P. G. (1989). The dependence of lexical relatedness effects on syntactic connectedness. Journal of Experimental Psychology: Learning, Memory, \& Cognition, 15, 73-87.

Potter, M. C., Moryadas, A., Abrams, I., \& Noel, A. (1993). Word perception and misperception in context. Journal of Experimental Psychology: Learning, Memory, \& Cognition, 19, 3-22.

Rayner, K., Garrod, S., \& Perfetti, C. A. (1992). Discourse influences during parsing are delayed. Cognition, 45, 109-139.

Seidenberg, M. S., Tanenhaus, M. K., Leiman, J. M., \& BienkowSKI, M. (1982). Automatic access of the meanings of ambiguous words in context: Some limitations of knowledge-based processing. Cognitive Psychology, 14, 489-537. 
Sharkey, A. J. C., \& Sharkey, N. E. (1992). Weak contextual constraints in text and word priming. Journal of Memory \& Language, 31, 543-572.

SharkeY, N. E., \& Mitchell, D. C. (1985). Word recognition in a functional context: The use of scripts in reading. Journal of Memory \& Language, 24, 253-270.

Simpson, G. B., Peterson, R. R., Casteel, M. A., \& Burgess, C. (1989). Lexical and sentence context effects in word recognition. Joumal of Experimental Psychology: Learning, Memory, \& Cognition, 15, 88-97.

SINGER, M. (1976). Thematic structure and the integration of linguistic information. Journal of Verbal Learning \& Verbal Behavior, 15, 549-558.

StANOVICH, K. E., \& WEST, R. F. (1979). Mechanisms of sentence context effects in reading: Automatic activation and conscious attention. Memory \& Cognition, 7, 77-85.

Stanovich, K. E., \& West, R. F. (1981). The effect of sentence context on ongoing word recognition: Tests of a two-process theory. Journal of Experimental Psychology: Human Perception \& Performance, 7 , 658-672.

StANOVICH, K. E., \& WeST, R. F. (1983). On priming by a sentence context. Journal of Experimental Psychology: General, 112, 1-36.

SUH, S., \& TraBasso, T. (1993). Inferences during reading: Converging evidence from discourse analysis, talk-aloud protocols, and recognition priming. Journal of Memory \& Language, 32, 279-300.

TANenhaus, M. K., \& Spivey-KNowlton, M. J. (1995). Integration of visual and linguistic information in spoken language comprehension. Science, 268, 1632-1634.

WEST, R. F., \& STANOVICH, K. E. (1982). Source of inhibition in experiments of the effect of sentence context on word recognition. Journal of Experimental Psychology: Learning, Memory, \& Cognition, 25, 385-399.

Whitney, P., McKay, T., Kellas, G., \& Emerson, W. A., Jr. (1985). Semantic activation of noun concepts in context. Journal of Experimental Psychology: Learning, Memory, \& Cognition, 11, 126-135. WILLIAMS, J. N. (1988). Constraints upon semantic activation during sentence comprehension. Language \& Cognitive Processes, 3, 165-206.

\section{NOTE}

1. A fourth condition would complete the factorial crossing of focus (congruent/incongruent) and agency (congruent/incongruent). However, creating this condition would also involve changing other aspects of the sentence context, such as word order and the physical distance between the critical content nouns and the target. This would make it difficult to interpret the source of any differences observed in this condition relative to the others.

(Manuscript received January 13, 1997; revision accepted for publication September $25,1997$. 